Portland State University

PDXScholar

8-9-2019

\title{
Self-Disclosure and Physiological Responses among Adults who Stutter
}

Sulema Rodriguez

Portland State University

Follow this and additional works at: https://pdxscholar.library.pdx.edu/honorstheses

Let us know how access to this document benefits you.

\section{Recommended Citation}

Rodriguez, Sulema, "Self-Disclosure and Physiological Responses among Adults who Stutter" (2019). University Honors Theses. Paper 789.

https://doi.org/10.15760/honors.807

This Thesis is brought to you for free and open access. It has been accepted for inclusion in University Honors Theses by an authorized administrator of PDXScholar. Please contact us if we can make this document more accessible: pdxscholar@pdx.edu. 
Self-Disclosure and Physiological Responses among Adults who Stutter

$$
\text { by }
$$

\section{Sulema Rodriguez}

An undergraduate honors thesis submitted in partial fulfillment of the requirements for the degree of

Bachelor of Science

in

University Honors

and

Speech and Hearing Sciences

Thesis Adviser

Dr. Megann McGill

Portland State University

2019 


\begin{abstract}
Purposes: (1) To explore self-disclosure, physiological and affective responses in easy and difficult speaking situations, (2) to investigate physiological and affective responses in self-disclosure and no self-disclosure speaking contexts, (3) to examine types of self-disclosure statements used along with physiological responses, (4) and to gain an understanding of reasons why and how adults who stutter choose to self-disclose or not self-disclose about their stuttering.
\end{abstract} Method: Four adults who stutter were randomly assigned to self-disclosure and non self-disclosure speaking contexts. Heart rate, skin conductance, and affective responses were measured during the following focus areas: 1) start baseline, 2) anticipation of the easy speaking situation, 3) the easy speaking situation, 4) anticipation of the difficult speaking situation, 5) the difficult speaking situation, and 6) end baseline. An informational interview to understand the participants' use of or lack of self-disclosure in their daily lives was then conducted.

Results: Skin conductance responses were comparable between self-disclosure and non self-disclosure groups. When it came to the participants' heart rate (BPM), all but one focus area had a statistically significant difference between the BPM recorded for the self-disclosure group $(\mathrm{M}=35.88, \mathrm{SD}=3.77)$ compared to the non self-disclosure group $(\mathrm{M}=49.54, \mathrm{SD}=1.54)$ for the End Baseline; $p=0.04$ (between-group). Affectively, participants who did not self-disclose reported the same affective responses pre- and post-experiment, while participants who did self-disclose reported different affective responses pre- and post-experiment. Participants also expressed that self-disclosing was dependent on the familiarity of the listener or situation. Also, most participants stated feeling "at ease" or a "pressure" was lifted off when they self-disclosed. Most participants also shared that they self-disclosed as a part of their first interaction with 
someone or when meeting someone for the first time. Furthermore, when asked about their reactions to engaging in the most difficult and easiest speaking situations most participants were surprised by their feelings.

Conclusion: There was not a statistically significant difference in the between-group heart rate and skin conductance results, but there was during the end of the baseline of the BPM measurements. It was also suggested that the anticipation of easy or difficult speaking situations (SC and HR) may be influenced based on familiarity or comfortableness of situation. Participants who did not self-disclose reported the same affective responses pre- and post-experiment, while participants who did self-disclose reported different affective responses pre- and post-experiment. Additionally, the informational interview gave insight into how the participants' perceived fear of a speaking situation was different than anticipated. The interview provided information about the situations that participants self-disclose most often and how they self-disclose. This study also revealed that self-disclosure is still a valuable tool that can ease conversation for the speaker. These results may help clinicians to inform their therapy by considering multiple variables that contribute to stuttering and how they change depending on the client's experiences. 


\section{Introduction}

Stuttering is a fluency disorder which is characterized by prolongations, repetitions, and blocks, which disrupt the flow of speech (Guitar, 2014). There are multiple factors affecting stuttering, including physiological, psychological, environmental, and linguistic (Guitar 2006; 2016; Kang et.al, 2010; Sitek et.al; Smith \& Weber, 2017). Self-disclosure has been shown to improve listeners' perceptions and attitudes towards people who stutter in a positive manner (e.g., Byrd, McGill, Gkalitsiou, \& Cappellini, 2017; Byrd, Gkalitsiou, McGill, Kelly \& Reed, 2016; Lincoln, Brinker-Katz, 2017). Additionally, lower quality of life for people who stutter has been associated with lower levels of self-disclosure (Boyle, Milewski, \& Beita-Ell, 2018). Yet, limited research has explored the physiological and affective changes that speakers who stutter experience when they self-disclose (or do not self-disclose) their stuttering.

Previous studies have provided evidence suggesting that there is an impact of psychological and environmental contexts on stuttering severity (see Furnham \& Davis, 2004, for review; Tran, Blumgart, \& Craig, 2011). Physiological responses have also been noted in the anticipation of stuttering (e.g., Bowers, Saltuklaroglu, \& Kalinowski, 2012). Bowers and colleagues (2012) examined the relationship between anticipatory autonomic arousal and stuttering during reading tasks. In this study, 13 adults who stutter stated their "feared" sounds, which were the sounds they believe would elicit more stuttering. The participants were then asked to read four stimuli passages which were divided by feared (F) and neutral (N) phonemes. These stimuli sets were either read solo $(\mathrm{S})$ or by choral accompaniment $(\mathrm{C})$, which created the following conditions: FS, FC, NS, and NC. Bowers and colleagues (2012) found that people who stutter presented with decreased skin conductance when stuttering was eliminated and skin 
conductance was generally unrelated to occurrences of stuttering events. They also reported that people who stutter exhibited more instances of slowed heart rate when a skin conductance response occurred. Bowers et al. (2012) concluded that the physiological responses of people who stutter were best determined by the anticipation/possibility of stuttering, rather than speech outcome (i.e. fluent or stuttered). These results suggest the importance of further exploring the anticipation of stuttering and its effects on the speaker who stutters in a variety of contexts other than reading.

Self-disclosure is a practice that involves sharing personal information to others (Derlaga \& Berg, 1987). Byrd and colleagues (2017) randomly assigned 173 participants to watch two of the four following possible videos: male self-disclosure, male non self-disclosure, female self-disclosure, and female non self-disclosure. Participants were then asked to complete a survey to assess their perceptions of the speakers. Byrd and colleagues (2017) reported that those who self-disclosed were perceived as being more friendly, outgoing, and confident compared to those who did not self-disclose. Furthermore, speakers who chose not to self-disclose were more likely rated as unfriendly and shy compared to those who did self-disclose.

There is also evidence suggesting that using self-disclosure at the beginning of an interaction generates more positive reactions from the listener as compared to self-disclosure at the end of an interaction (Healey, Gabel, Daniels, \& Kawai, 2007). Bryd, Croft, Gkalitsiou, and Hampton (2017) reinforced these findings through their study which found that informative statements at the beginning of an interaction generated more positive observer ratings than a non self-disclosure statement. They found that people who stutter tend to employ different types of self-disclosure statements: direct, apologetic, and informative. These types of self-disclosure 
statements used vary depending on the individual and the social setting (McGill, Nguyen, Siegel \& Rodriguez, 2018). A recent study found that people who stutter who used informative self-disclosure statements were rated more positively by observers compared to those who did not self-disclose. On the other hand, participants who stutter who used apologetic statements did not generate significantly better observer ratings than choosing not to self-disclose (Byrd, Croft, Gkalitsiou, \& Hampton, 2017). Taken together, this research supports the clinical utility of self-disclosure for adults who stutter when they use a non-apologetic self-disclosure statement.

\section{Relevance and Purpose}

Previous studies have been conducted regarding self-disclosure and physiological response, but these have yet to be studied simultaneously. Self-disclosure studies have predominantly focused on the observer's changed perceptions, rather than the impact on the person who stutters (Byrd, et.al., 2017; Bowers, et al., 2012; Healey, et.al., 2007; Guntupalli, Kalinowski, Nanjundeswaran, Saltuklaroglu, \& Everhart, 2006). Additionally physiological response studies with people who stutter have only used predetermined reading tasks (Alm, 2004; Bowers, et.al., 2012).

\subsection{Purpose and Study Aims}

The current study aims to explore self-disclosure and physiological responses of people who stutter in both an easy and a difficult speaking situation. This research is part of a movement towards the social model of disability, which creates an emphasis on the person who stutters and improving their quality of life, rather than "fixing" their stuttering and achieving $100 \%$ fluency (Bailey, Harris \& Simpson, 2014). Previously, Dietrich and Roaman (2001) explored the physiological responses of adults who stutter across a variety of speaking situations. 
The current study is an adaptation and extension of Dietrich and Roaman (2001) and Bowers and colleagues (2012) previous work. Specifically, we are interested in the physiological and affective responses of adults who stutter in a variety of speaking situations in which the participant may or may not self-disclose their stuttering.

In the current study, participants' physiological and affective responses to self-disclosing (or not self-disclosing their stuttering) were monitored in an easy and a difficult speaking situation. Furthermore, we conducted within-group and between-group analyzes of both the self-disclosure and non self-disclosure conditions during start and end baseline, anticipation of easy and difficult speaking situation, and once participants engaged in the easy and difficult and speaking situation. We hypothesized that participants who stutter would report differences in their valence, arousal, and dominance prior to and after engaging in the experimental tasks, but recognize that individual differences may supersede these trends. This research will enable greater theoretical understanding of factors thought to contribute to physiological response change in various social contexts, improve speech-language treatment models, and potentially impact the development of clinical training tools for stuttering. 


\section{Method}

\subsection{Participants}

Four adult participants who stutter $(\mathrm{M}=29.75$ years old $)$ participated in this study. All participants were recruited through the National Stuttering Association, online flyers via the Portland State University Stuttering Lab, online postings to social media groups for people who stutter, and through word of mouth. Three out of the four participants reported that they previously or currently are enrolled in speech therapy. One participant reported that they were enrolled in speech therapy for two months, while another participant reported that have been participating in speech therapy for three years.

\subsection{Pre-Experimental Procedures}

Participants completed the experiment during one session lasting approximately $1.5-2$ hours hours. All experimental conditions were conducted in the Portland State University Speech \& Language Clinic and the Portland State University Stuttering Lab, located in the University Center Building. Participants provided written consent prior to the initiation of the experiment, as required by the Institutional Review Board \#196339-18. Participants completed an initial inclusionary questionnaire, answering questions about past speech therapy and medical history. Participants were then randomly assigned to one of two experimental groups: self-disclosure or non self-disclosure.

Prior to beginning the experimental tasks, participants were asked to wash their hands with water and thoroughly dry them prior skin conductance electrode placement. Skin conductance electrodes were then placed on the nondominant hand and skin was not abraded. 


\subsection{Physiological and Affective Measures}

Heart rate was evaluated and analysed using "BIOPAC" for electrocardiogram recordings. Skin conductance was also measured and analysed using BIOPAC MP 160 and two amplifier modules (i.e. EDA 100d and ECG100d). Also, calibration was ensured by using two automatically-set buttons, "auto-configure" and "calibrate" in the AcqKnowledge 5.0 software.

Additionally, pre- and post- values for participant responses of the Self-Assessment Manikin were recorded. The Self-Assessment Manikin is a nonverbal, pictorial assessment that is used to measure affective responses through the following categories: valence, arousal, and dominance (Bradley \& Lang, 1994). Valence describes how pleasant a stimuli is, arousal indicates the intensity of an emotional response caused by stimuli, and dominance represents how much control a stimuli has (Warriner, Kuperman, \& Brysbaert, 2013). The Self-Assessment Manikin measures valence, arousal, and dominance associated with viewing each icon (see Appendix A). For the purposes of our study, a nine-point scale Self-Assessment Manikin was utilized. On the left side of the valence scale (unhappy-happy), the icon appears to be unhappy, while on the right side it appears to be smiling. The valence scale demonstrates pleasant, happy, or positive valence on the left side, while on the right side it uses unpleasant, unhappy, or unsatisfied. For the arousal scale (calm-excited), the icon appears to be calm on the left side and excited on the right side (Geethanjali, Adalarasu, Hemapraba, Kumar, \& Rajasekeran, 2017). The arousal scale demonstrates various levels of agitation showing a relaxed, calm, or unaroused icon on the left side and stimulated, excited, or aroused icon on the right side. Additionally, the level of intensity is demonstrated with accompanying images of exploding bursts on the icon's abdomen for a high intensity arousal and a small dot for low intensity (Bynion \& Feldner, 2017). 
Lastly, for the dominance scale the icon is dependent (small size) on the left side and independent (large size) on the right side (Adalarasu, Hemapraba, Kumar, \& Rajasekeran, 2017; Guntupalli, Everhart, Kalinowski, Nanjundeswaran, \& Saltuklaroglu, 2007). Participants were asked to mark an " $\mathrm{X}$ " on top of an icon or between two icons at pre- and post-experiment. Finally, after the experimental paradigm concluded, participants engaged in a post-experimental interview (see Appendix B) to share their experiences and reactions to using self-disclosure (or non self-disclosure) in the experiment.

\subsubsection{Experimental Procedures}

For heart rate measures, Lead 2 (Einthoven's Triangle II) was utilized. Einthoven's Triangle II requires a negative lead to be placed on the right clavicle, a positive lead to be placed on the left lower rib, and a ground lead to be placed on the left clavicle. To assist with improved connection, an abrasive gel (ELPREP) was placed on the electrode sites with a dry cotton towel to remove dead skin cells that may increase electrical impedance. Additionally, electrode gel (GEL100) was placed on electrode sites to help improve signaling.

Once electrodes were placed on participants, they were asked to sit comfortably for about 10 minutes prior to data collection. Trial run measurements were then recorded for 2 minutes to ensure that the software and electrodes were working properly. Start baseline was recorded for 5 minutes, then speech-anticipation was recorded for 10 seconds after the explanation of instructions for both the easy and difficult speaking situations. Twenty seconds after participants confirmed they understood the directions, data was recorded for the speaking situation.

Participant speaking time during difficult and easy speaking situations ranged from 1-3 minutes. For the easy speaking situation, a choral reading condition was utilized. In this choral reading, 
participants were asked to read the "Rainbow Passage" (Appendix C) in unison with the experimenter. For the difficult speaking situation, a cold call to a local coffee shop was utilized. Participants were instructed to call a coffee shop and ask for the days and hours the location was open. In addition, participants asked for the price of substituting soy for regular milk, using their own words. These situations were based on the following criteria: replicability in the lab and arousal in physiological measurements (Dietrich \& Roaman, 2001).

\subsubsection{De-briefing and Post-Experimental Procedures}

After completion of the physiological experimental tasks, participants engaged in a 12-35 minute interview about their use of self-disclosure. Participants were asked to describe why they choose to self-disclose or not self-disclose their stuttering in everyday life, the situations in which they self-disclose, how they self-disclose, and their overall feelings of engaging in the experimental speaking tasks (see Appendix B). After the interview, participants were debriefed on the purpose of the study and how the methodology was constructed. This included discussing the selection of difficult and easy speaking situations, and how physiological measures were recorded.

Open coding was utilized to analyze all possible participant meanings without forming a hypothesis prior to transcribing. Once open coding was completed, all transcriptions were then looked at together to find similar participant experiences, which helped generate final themes. These final themes were then divided into subthemes that described these experiences more in-depth, which were accompanied by participant examples (McGill, Cullen, \& Webb, 2019). 


\subsection{Data Processing and Analysis}

\subsubsection{Data Processing and Cleaning}

Raw physiological data was recorded using the AcqKnowledge 5.0 BIOPAC software. After data was recorded for all participants, a copy was created for further analysis so that the original data was unaltered. Then, individual participant's data was cleaned post-experiment using various filters to create valid data without noise or computational overload. To score skin conductance data, the waveform was resampled at $62.5 \mathrm{kHZ}$ from the original $2000 \mathrm{kHZ}$. This resampling reduces the data processing time by reducing computational overload and providing a valid analysis of the data. For artifact removal, a smoothing filter at 63 samples per second was run on the skin conductance waveform. Phasic skin conductance was constructed using a using a high-pass filter at $.05 \mathrm{~Hz}$, description provided by Bowers and colleagues (2012). Also, skin conductance response threshold was set at .01 microsiemens, which assists in the identification of the onset of a skin conductance response. Additionally, a low-pass filter was set at $1.0 \mathrm{~Hz}$, based on BioPac and Zhang, Kalinowski, Saltuklaroglu, and Hudock (2010) recommendations.

After filters were applied, focus areas were placed for the following conditions: trial run, start baseline, anticipation of the easy speaking situation, easy speaking situation, anticipation of the difficult speaking situation, difficult speaking situation, and end baseline. Skin conductance responses were identified using the "Locate SCRs" command in the AcqKnowledge 5.0 software, where appropriate and filtered channel was selected. Electrodermal activity and heart rate was analyzed using mean and amplitude using the following commands in the AcqKnowledge 5.0 software: mean, delta $t$ (seconds), event count (skin conductance response), 
beats per minute, and calculation (event count divided by delta $t$ ). This calculation provides the skin conductance rate.

\subsubsection{Data Aggregation and Analysis}

Once all individual data was cleaned, the files were exported to Microsoft Excel for analysis. For heart rate, beats per minute were automatically averaged for each participant within each of the following conditions: 1) baseline, 2) the easy speaking situation, 3) the difficult speaking situation. See Figure 2 for a visual representation of the focus areas and heart rate (BPM) for one participant. 
Figure 1. A screenshot of participant heart rate (beats per minute) on the BioPac AcqKnowledge 5.0 software.

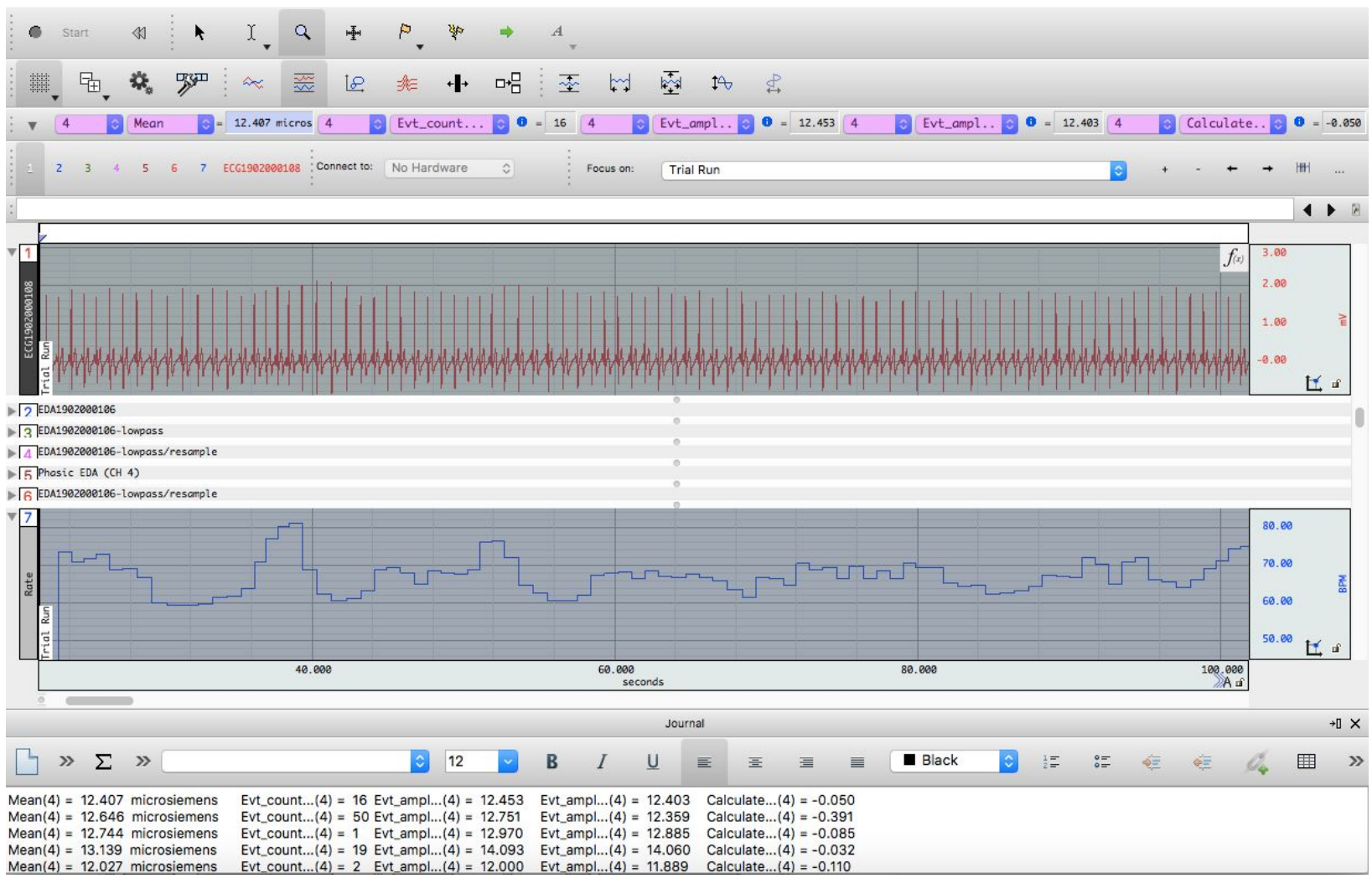

For skin conductance data, two variables were considered: skin conductance level and skin conductance rate. For skin conductance level, the offset of the event waveform was subtracted from the onset of the waveform across all focus areas for each participant, resulting in an amplitude delta value. For skin conductance rate, the waveform delta was divided by the event count. See Figure 2 for a visual representation of the focus areas, event waveform onsets and offsets, and event counts for one participant. 
Figure 2. A screenshot of the focus areas, event waveform onsets and offsets, and event counts for one participant.

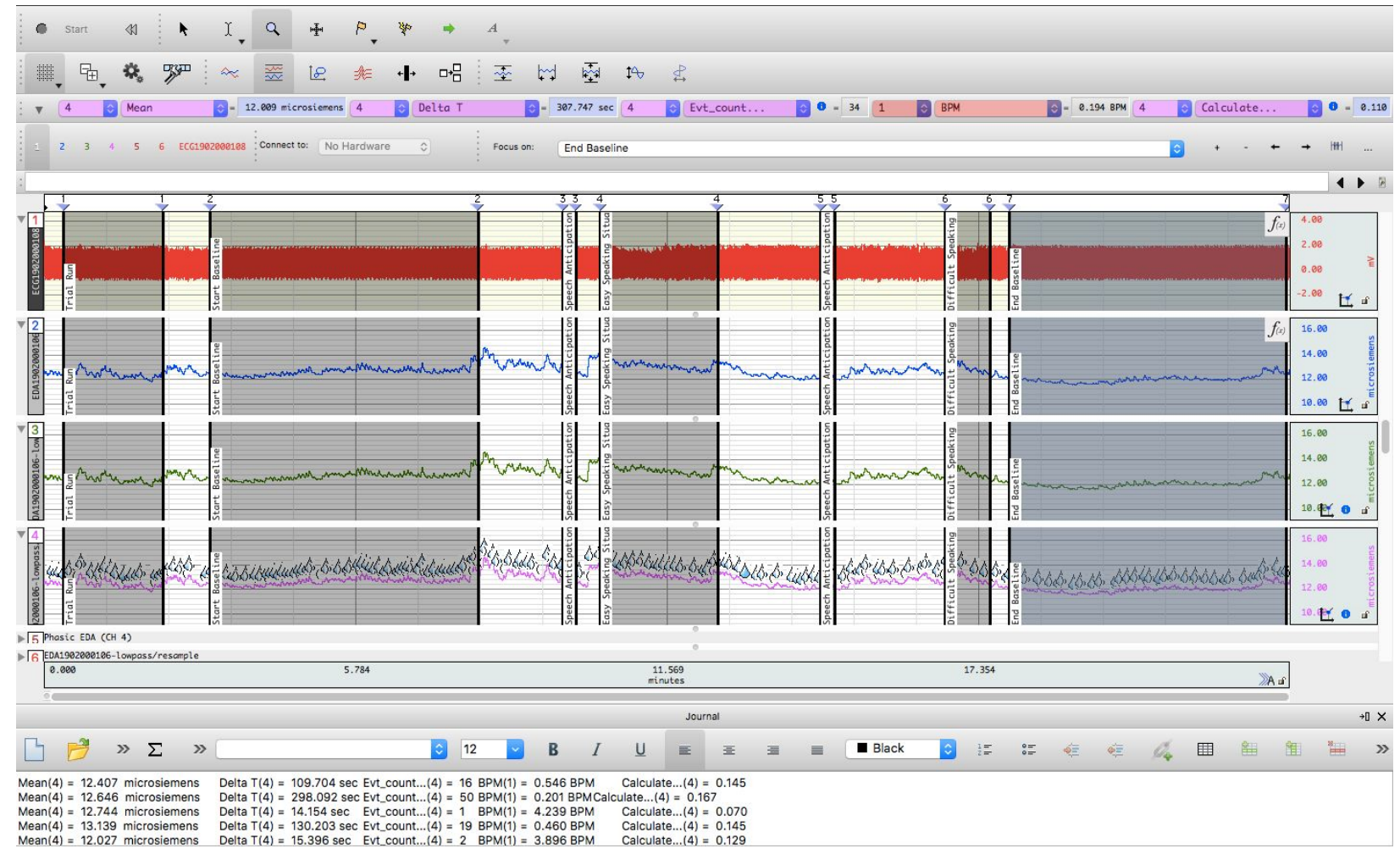

Data was analyzed using an independent samples t-test to compare the two experimental groups (i.e. self-disclosure and non self-disclosure). Other statistical analyses were not conducted due to the limited sample size.

\section{Results}

\subsection{Physiological Response Results}

\subsubsection{Between-Group Heart Rate Results}

When heart rate response (beats per minute, BPM) was compared between the self-disclosure and non self-disclosure groups, the following was noted. There was not a statistically significant difference between the BPM of the self-disclosure group $(M=44.78$, 
$\mathrm{SD}=2.53)$ and the $\mathrm{BPM}$ of the non self-disclosure group $(\mathrm{M}=104.59, \mathrm{SD}=52.13)$ for Start

Baseline; $p=0.25$. There was not a statistically significant difference between the self-disclosure group $(\mathrm{M}=42.58, \mathrm{SD}=2.67)$ and the non self-disclosure group $(\mathrm{M}=184.97, \mathrm{SD}=162.37)$ for the Easy Speaking Situation; $p=0.34$. There was not a statistically significant difference between the self-disclosure group $(\mathrm{M}=32.08, \mathrm{SD}=20.66)$ and the non self-disclosure group $(\mathrm{M}=38.26$, $\mathrm{SD}=7.39$ ) for the Difficult Speaking Situation; $p=0.73$. Interestingly, there was a statistically significant difference between the BPM recorded for the self-disclosure group ( $M=35.88$, $\mathrm{SD}=3.77)$ compared to the non self-disclosure group $(\mathrm{M}=49.54, \mathrm{SD}=1.54)$ for the End Baseline; $p=0.04$.

\subsubsection{Within-Group Skin Conductance Response Results}

There was not a statistically significant difference comparing Start Baseline $(\mathrm{M}=-0.75$, $\mathrm{SD}=0.04)$ to End Baseline $(\mathrm{M}=-0.60, \mathrm{SD}=0.06)$ conditions for the self-disclosure group; $p=$ 0.06. There was not a statistically significant difference comparing the Anticipation of the Easy Speaking Situation $(\mathrm{M}=-0.11, \mathrm{SD}=0.16)$ to the Anticipation of the Difficult Speaking Situation $(\mathrm{M}=-0.09, \mathrm{SD}=0.13)$ conditions for the self-disclosure group; $p=0.94$. Finally, there was not a statistically significant difference comparing the Easy Speaking Situation $(\mathrm{M}=-0.71, \mathrm{SD}=0.04)$ to the Difficult Speaking Situation ( $\mathrm{M}=-.53, \mathrm{SD}=0.34)$ conditions for the self-disclosure group; $p=$ 0.56 .

The within-group responses for the non self disclosure group were similarly non significant. There was not a statistically significant difference comparing Start Baseline $(\mathrm{M}=-1.73, \mathrm{SD}=0.89)$ to End Baseline $(\mathrm{M}=-0.82, \mathrm{SD}=0.03)$ conditions for the non self-disclosure group; $p=0.32$. There was not a statistically significant difference comparing the Anticipation of 
the Easy Speaking Situation $(\mathrm{M}=-0.95, \mathrm{SD}=1.34)$ to the Anticipation of the Difficult Speaking Situation $(\mathrm{M}=-0.89, \mathrm{SD}=0.38)$ conditions for the non self-disclosure group; $p=0.59$. Finally, there was not a statistically significant difference comparing the Easy Speaking Situation $(\mathrm{M}=-3.08, \mathrm{SD}=2.71)$ to the Difficult Speaking Situation $(\mathrm{M}=-0.64, \mathrm{SD}=0.12)$ conditions for the non self-disclosure group; $p=0.41$.

\subsubsection{Between-Group Skin Conductance Response Results}

There was not a statistically significant difference between the self-disclosure group $(\mathrm{M}=-0.75, \mathrm{SD}=0.04)$ and the non self-disclosure group $(\mathrm{M}=-1.73, \mathrm{SD}=0.89)$ for Start Baseline; $p$ $=0.35$. There was not a statistically significant difference between the self-disclosure group $(\mathrm{M}=-.11, \mathrm{SD}=0.155)$ and the non self-disclosure group $(\mathrm{M}=-0.95, \mathrm{SD}=1.33)$ for Anticipation of the Easy Speaking Situation; $p=0.47$. There was not a statistically significant difference between the self-disclosure group $(\mathrm{M}=-0.71, \mathrm{SD}=0.04)$ and the non self-disclosure group $(\mathrm{M}=-3.08, \mathrm{SD}=2.71)$ for the Easy Speaking Situation; $p=0.43$. There was not a statistically significant difference between the self-disclosure group $(\mathrm{M}=-0.09, \mathrm{SD}=0.13)$ and the non self-disclosure group $(\mathrm{M}=-0.89, \mathrm{SD}=0.38)$ for Anticipation of the Difficult Speaking Situation; $p$ $=0.11$. There was not a statistically significant difference between the self-disclosure group $(\mathrm{M}=-0.53, \mathrm{SD}=0.34)$ and the non self-disclosure group $(\mathrm{M}=-0.63, \mathrm{SD}=0.12)$ for the Difficult Speaking Situation; $p=0.63$. There was not a statistically significant difference between the self-disclosure group $(\mathrm{M}=-0.60, \mathrm{SD}=0.06)$ and the non self-disclosure group $(\mathrm{M}=-0.83$, $\mathrm{SD}=0.03$ ) for the End Baseline; $p=0.07$; however, this comparison was approaching significance. 
In addition to the statistical analyses, the following observations were noted in relation to skin conductance rate responses. Three participants had skin conductance events for the anticipation of the Difficult Speaking Situation as compared to two participants for the Easy Speaking Situation. P3 (self-disclosure assignment) and P4 (non self-disclosure assignment) had no skin conductance rate responses for the Anticipation of the Difficult Speaking Situation, while P1 (self-disclosure assignment) had no skin conductance rate response for the Anticipation of the Easy Speaking Situation.

\subsection{Affective Response Results}

Participant responses to the Self-Assessment Manikin were obtained prior to the physiological experimental procedures (pre) and immediately upon completion of the experiment (post). Although differences in the mean responses between participants who utilized a self-disclosure statement and those participants who did not utilize a self-disclosure statement were observed, these differences were not statistically significant.

\subsubsection{Within-Group Self-Assessment Manikin Results}

There was not a statistically significant difference in the scores for Valence (Pre) $(\mathrm{M}=7$, $\mathrm{SD}=2.83)$ and Valence (Post) $(\mathrm{M}=7, \mathrm{SD}=0)$ for the self-disclosure condition; $p=1$. There was not a statistically significant difference in the scores for Arousal (Pre) $(\mathrm{M}=2, \mathrm{SD}=1.41)$ and Arousal (Post) $(\mathrm{M}=4.5, \mathrm{SD}=2.12)$ for the self-disclosure condition; $p=0.30$. There was not a statistically significant difference in the scores for Arousal $(\mathrm{Pre})(\mathrm{M}=2, \mathrm{SD}=1.41)$ and Dominance (Post) $(\mathrm{M}=6, \mathrm{SD}=1.41)$ for the self-disclosure condition; $p=0.55$. All t-tests completed for the within-group analyses of the non self-disclosure condition yielded $p$-values of 1, indicating no response changes between pre- and post-assessment for that group. 


\subsubsection{Between-Group Self-Assessment Manikin Results}

There was not a statistically significant difference between the self-disclosure group $(\mathrm{M}=7, \mathrm{SD}=0)$ and the non self-disclosure group $(\mathrm{M}=8, \mathrm{SD}=1.41)$ for Valence (post); $p=0.42$. There was not a statistically significant difference between the self-disclosure group ( $M=4.5$, $\mathrm{SD}=2.12)$ and the non self-disclosure group $(\mathrm{M}=2, \mathrm{SD}=1.41)$ for Arousal (post); $p=0.30$. There was not a statistically significant difference between the self-disclosure group $(\mathrm{M}=6, \mathrm{SD}=1.41)$ and the non self-disclosure group $(\mathrm{M}=4, \mathrm{SD}=1.41)$ for Dominance (post); $p=0.30$. Although there were not statistically significant findings for these analyses, the mean ratings from the self-disclosure group demonstrated a shift toward significance with changes across all three categories noted in their self-reports.

Table 1. Pre- and Post-Experimental Self-Assessment Manikin Scores

\begin{tabular}{|c|c|c|c|c|c|c|c|}
\hline Participant & Condition & $\begin{array}{c}\text { Valence } \\
\text { (Pre) }\end{array}$ & $\begin{array}{c}\text { Arousal } \\
\text { (Pre) }\end{array}$ & $\begin{array}{c}\text { Dominance } \\
\text { (Pre) }\end{array}$ & $\begin{array}{c}\text { Valence } \\
\text { (Post) }\end{array}$ & $\begin{array}{c}\text { Arousal } \\
\text { (Post) }\end{array}$ & $\begin{array}{c}\text { Dominance } \\
\text { (Post) }\end{array}$ \\
\hline P1 & Self-Disclosure & 5 & 3 & 6 & 7 & 6 & 7 \\
\hline P2 & $\begin{array}{c}\text { Non } \\
\text { self-Disclosure }\end{array}$ & 7 & 3 & 5 & 7 & 3 & 5 \\
\hline P3 & Self-Disclosure & 9 & 1 & 4 & 7 & 3 & 5 \\
\hline P4 & $\begin{array}{c}\text { Non } \\
\text { self-Disclosure }\end{array}$ & 9 & 1 & 3 & 9 & 1 & 3 \\
\hline
\end{tabular}

P1 pre-experimental affective self-ratings were as follows: neutral (valence), dull (arousal), and powerful (dominance), while their post-experimental scores were pleased (valence), wide-awake (arousal), powerful (dominance). P2 had the same affective self-ratings pre- and post-experiment: pleased (valence), dull (arousal), and neutral (dominance). 
Additionally, P3 pre-experimental affective self-ratings were the following: pleasant (valence), calm (arousal), and neutral (dominance), while their post-experimental scores were pleased (valence), dull (arousal), and neutral (dominance). Lastly, P4's pre- and post-experimental affective scores remained the same, as follows: pleasant (valence), calm (arousal), and powerlessness (dominance).

Within the SD group, valence remained the same from pre- to post-assessment. Interestingly, within the SD group, arousal and dominance both changed (although not statistically significantly) between pre- and post-assessment. These changes in the self-assessment manikin were not noted for the NSD group, which maintained all scores at the same level for pre- and post-. Pre-experiment P1 had valence, arousal, and dominance scores of 5,3 , and 6 , while post-experiment scores changed to 7, 6, and 7. P2 had valence, arousal, and dominance scores of 9,1 , and 4 , while post-experiment these scores changed to 7, 3, and 5 .

\subsection{Qualitative Interview Results}

Participant responses to semi-structured interview questions were coded in vivo and then aggregated to form themes. See Table 2 for a display of the themes and subthemes which emerged from participant responses about their use, preference, and challenges of implementing a self-disclosure statement in their daily lives. Additionally, participant quotes are included as evidence of these themes.

Table 2. Participants examples using themes and subthemes

\begin{tabular}{|l|l|l|}
\hline Theme & Subtheme & Participant Examples \\
\hline $\begin{array}{l}\text { Situations where } \\
\text { participants } \\
\text { self-disclose }\end{array}$ & $\begin{array}{l}\text { Self-Disclosing } \\
\text { during job } \\
\text { interviews }\end{array}$ & $\begin{array}{l}\text { "Uh, primarily they would be during like interviews, } \\
\text { mainly. I would say: "I stammer, so I hope that you } \\
\text { understand, basically, and I may stumble on some } \\
\text { words here or there."(P2) }\end{array}$ \\
\hline
\end{tabular}




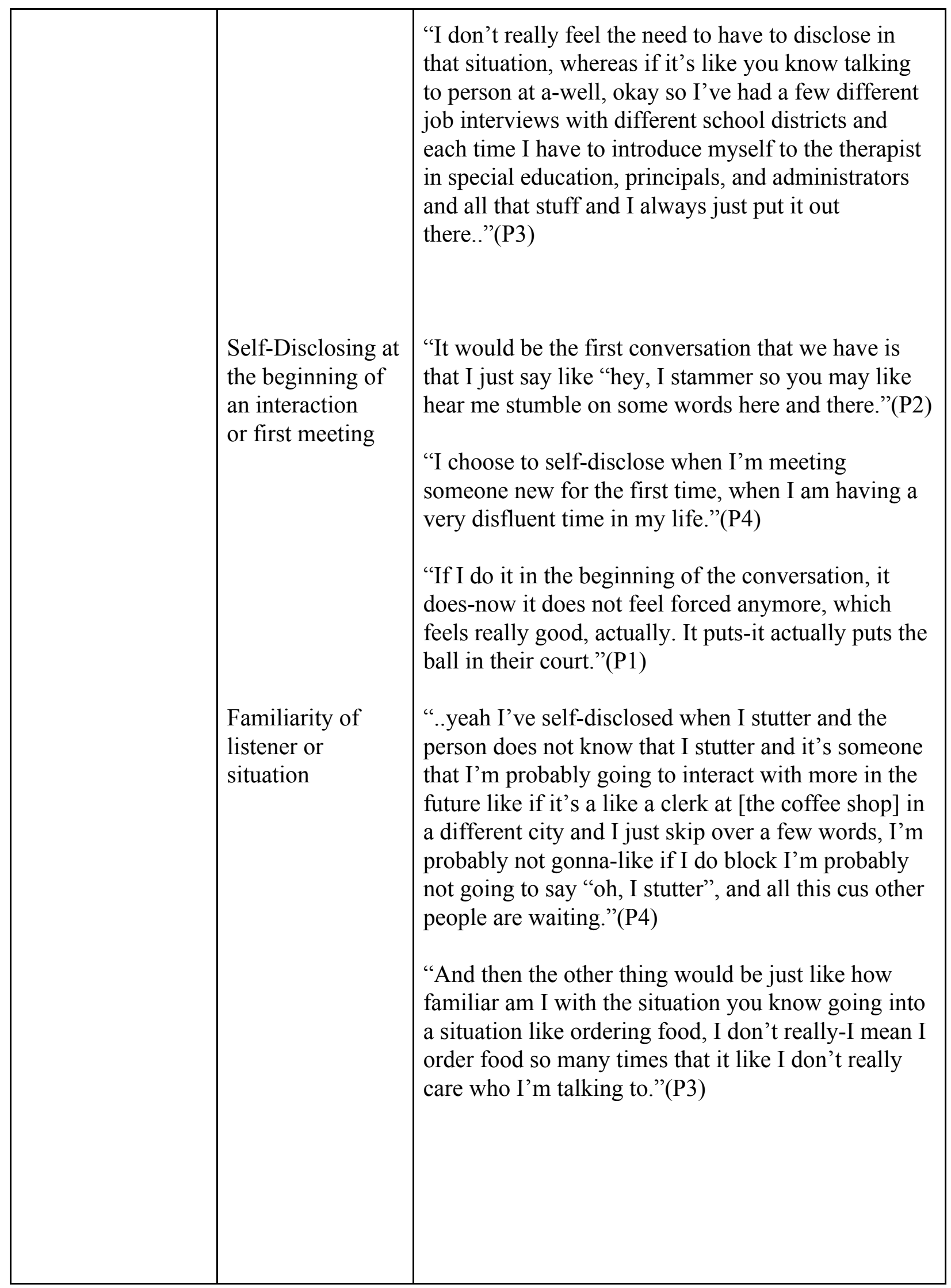




\begin{tabular}{|c|c|c|}
\hline & $\begin{array}{l}\text { Self-Disclosing } \\
\text { on the phone }\end{array}$ & $\begin{array}{l}\text { "Definitely speaking on the phone. That's really the } \\
\text { main one. I also do it at work sometimes if I'm } \\
\text { speaking to clients for the first time as well, I don't } \\
\text { want them to be distracted while I'm giving them } \\
\text { information."(P1) } \\
\text { "If it's like someone at the end of the phone line or a } \\
\text { clerk like another customer service person that } \\
\text { clearly doesn't understand why they're not getting a } \\
\text { signal from me like maybe they-they're probably } \\
\text { thinking that the cell's dropped, and then I would } \\
\text { just blurt it out, and then they would be more } \\
\text { under-be more informed about what's going on } \\
\text { communication-wise."(P4) }\end{array}$ \\
\hline $\begin{array}{l}\text { Severity and } \\
\text { self-disclosure }\end{array}$ & $\begin{array}{l}\text { Presence of } \\
\text { stuttering } \\
\text { Lack of stuttering }\end{array}$ & $\begin{array}{l}\text { "I'm not sure like the reasoning why but it all kind } \\
\text { of depends on how bad I'm stuttering that day } \\
\text { basically, yeah."(P2) } \\
\text { "I don't self-disclose when I'm in a situation where } \\
\text { you know I'm not stuttering." (P4) }\end{array}$ \\
\hline $\begin{array}{l}\text { Benefits of } \\
\text { self-disclosure }\end{array}$ & $\begin{array}{l}\text { Self-Disclosing } \\
\text { for both the } \\
\text { listener and } \\
\text { speaker } \\
\text { Feeling at ease }\end{array}$ & $\begin{array}{l}\text { "It's a combination of both. I feel like it would put } \\
\text { both of us or yeah both of us at ease, basically." (P2) } \\
\text { "Yeah, it takes the pressure off of me, and then they } \\
\text { understand as well what's going on, so 'cus most } \\
\text { people still don't know what stuttering looks like } \\
\text { when people are like in a hard block, they think } \\
\text { stuttering is just repetition. So they really don't } \\
\text { understand, and so it's for both parties."(P4) } \\
\text { "It feels good, it feels like "oh, I'm going to explain } \\
\text { and get myself out of this uncomfortable or } \\
\text { unknown situation that me and this other person are } \\
\text { in the last few seconds."(P4) }\end{array}$ \\
\hline Reflections & $\begin{array}{l}\text { Reactions to easy } \\
\text { and difficult } \\
\text { speaking }\end{array}$ & $\begin{array}{l}\text { Well, surprisingly the reading portion wasn't like } \\
\text { that bad I stammered like maybe once or twice, but } \\
\text { the phone one I was like anticipating to be worse but }\end{array}$ \\
\hline
\end{tabular}




\begin{tabular}{|l|l|l|}
\hline situations & $\begin{array}{l}\text { all in all it's not as bad as I thought it would have } \\
\text { been."(P2) }\end{array}$ \\
"You know definitely calling was easier, I felt. I felt \\
like I was trying to keep up with you on the passage. \\
Yeah, I felt- both of them I felt fine. Definitely \\
calling when I got tripped up on soy. It was a bit of a \\
stressor because you can't really change. I could of \\
you know with the "hours of operation" I could have \\
said you know "what time are you open everyday?" \\
or "what are your hours?". I can always change that, \\
but switching from-you can't really switch the word \\
"soy" to anything else."(P1)
\end{tabular}




\begin{tabular}{|c|c|c|}
\hline & & $\begin{array}{l}\text { "Yeah, it takes the pressure off of me and then they } \\
\text { understand as well what's going on, so 'cus most } \\
\text { people still don't know what stuttering looks like } \\
\text { when people are like in a hard block, they think } \\
\text { stuttering is just repetition."(P4) }\end{array}$ \\
\hline \multirow[t]{2}{*}{$\begin{array}{l}\text { How they } \\
\text { self-disclose }\end{array}$} & Verbal & $\begin{array}{l}\text { "I would just-it seems-I like to disclose in a way } \\
\text { that's not a big deal. This is just something that's a } \\
\text { part of me, so you don't have to treat me differently } \\
\text { or you know worry about me. This is just who I am } \\
\text { and what happens from time to time." (P1) } \\
\text { "It's a combination of both. I feel like it would put } \\
\text { both of us or yeah both of us at ease, basically." (P2) } \\
\text { "I often disclose verbally in the moment of speaking } \\
\text { to someone." (P4) }\end{array}$ \\
\hline & $\begin{array}{l}\text { Using both verbal } \\
\text { and non-verbal }\end{array}$ & $\begin{array}{l}\text { "It's proven to be useful to do both of them, but like } \\
\text { in my-so in my-prior to the relationship that I am in } \\
\text { right now I was on dating apps and I put it on my } \\
\text { profile that I stutter and not you know-again not } \\
\text { anybody else but for myself because my whole } \\
\text { intention behind being on these dating apps was to } \\
\text { be as authentic as I could be, so that I would ideally } \\
\text { attract the person that I actually wanted to spend } \\
\text { time with, not just putting on a front or mask to just } \\
\text { get a person to notice me. I was like "let me just be } \\
\text { as truthful about who I am as I possibly can be" and } \\
\text { that way a lot of those challenging conversations are } \\
\text { already not challenging anymore because it's already } \\
\text { out there. And I feel like I've advertised about it on } \\
\text { instagram and stuff like that. So even like through } \\
\text { posting stories where I'm actually talking about it or } \\
\text { posting on my timeline or I don't know is it called } \\
\text { timeline? Either like pictures from stuff I've done } \\
\text { for volunteer work or for work or any of the NSA } \\
\text { stuff." (P3) }\end{array}$ \\
\hline
\end{tabular}




\section{Discussion}

To review, the purposes of this study were to: (1) explore self-disclosure, physiological and affective responses using a hierarchy of speaking situations to assess self-perceived severity, (2) investigate physiological and affective responses in self-disclosure and nonself-disclosure speaking contexts, (3) examine types of self-disclosure statements used along with physiological responses, (4) and gain an understanding of reasons why and how adults who stutter choose to self-disclose or not self-disclose about their stuttering. In this portion of the paper, each of these purposes will be discussed in turn.

\subsection{Physiological Responses}

Within-group and between-group analyses were conducted for skin conductance, heart rate $(\mathrm{BPM})$, and affective measures. There were no statistically significant results in the participants' skin conductance measurements. When it came to the participants' heart rate (BPM), one focus area (i.e. End Baseline) was statistically significant different between the BPM recorded for the self-disclosure group, compared to the non self-disclosure group.

Additionally, there were some participants who had zero data recorded for skin conductance and heart rate for specific focus areas. This recording anomaly occurred in P2 and P3 during the Anticipation of the Easy Speaking Situation and in P1 during the Anticipation of a Difficult Situation. These results could not have been attributed to disclosure assignments because P1, P3, and P4 were assigned as follows: self-disclosure, non self-disclosure, and self-disclosure. Interestingly, P1 reported using the phone on a daily basis for work, so the lack of physiological results may be indicative of the reduced concern of making a phone call. An alternative explanation for this data anomaly could be that the equipment didn't record or 
participants did not produce skin conductance and heart rate responses. Also, for the anticipation conditions, data was recorded during a 10 second interval prior to initiating the speaking situation. This short interval of time (10 seconds) may have also contributed to the lack of recorded responses.

\subsection{Affective Responses}

As previously noted, the self-disclosure group showed differences in their affective responses, while the non self-disclosure group did not. P1's scores indicated more positive levels of valence and dominance and an increased level of arousal. In contrast, P3's valence and arousal increased post-experiment, while dominance remained the same. These results correspond with our hypothesis that the individual differences among participants who stutter would contribute to differences in their valence, arousal, and dominance prior to and after engaging in the experimental tasks. The self-disclosure group's results could have been impacted by the difficult speaking situation, which was the last situation measured and conducted. Participants were asked to complete their post-experiment self-assessment manikin approximately 6 minutes after engaging in the difficult speaking situation. A possible explanation for P3's results could have been because they engaged in this difficult situation prior to taking the self-assessment manikin. Another possibility is that more positive post-experiment results could have resulted from the speaking situation being completed or the feeling of a speaking task being easier than anticipated. These results could indicate that using self-disclosure will elicit varying affective responses, compared to not using self-disclosure, depending on the participant's personal experiences with the speaking situation. 


\subsection{Qualitative Interviews}

Healey et al. (2007) found that self-disclosing at the beginning of an interaction generated more positive reactions than self-disclosing at the end of an interaction. P1, P2, and P4 stated that they self-disclose as a part of their first interaction with someone or when meeting someone for the first time. P1 stated that if they self-disclosed at the beginning of an interaction, they felt that the conversation was less forced. Additionally, they expressed that the responsibility was placed on the listener, once they were informed about their stuttering. Healey et al. (2007) reported positive reactions were felt by the listener, rather than the speaker, when a person who stutters utilized a self-disclosure statement. In this study, the positive reactions were expressed by the speaker. Thus, implementation of a self-disclosure statement appears to benefit both the person who stutters and the listener.

Participants also expressed that self-disclosing was dependent on the familiarity of the listener or situation. P3 mentioned that they would not self-disclose if they were in a coffee shop that was in a different city, while other people are waiting in line. P4 expressed that they do not self-disclose if they are familiar with the situation. They used ordering food as an example, and they emphasize that they have ordered food so many times, that they don't care too much about the listener they are speaking to.

Most participants stated feeling "at ease" or a "pressure" being lifted off when they self-disclosed. These feelings were shared by both the listener and observer. Both P3 and P4 mentioned that there sometimes may be an element of confusion on the listeners' side because of their expectations of what a stutter should sound like. They mentioned that the listener expects to hear a repetition, rather than a block, which make the listener think that the speaker has forgotten 
an idea. Therefore, using a self-disclosure statement can increase mutual understanding between the listener and the person who stutters about what stuttering sounds like in real speech production.

Furthermore, both P1 and P3 expressed using and not using self-disclosure statements in their lives, depending on the situation/context. Some participants reported that they felt that calling a coffee shop was not an organic speaking opportunity since many of the answers to their questions could have been found online.

When asked about their reactions to engaging in the most difficult and easiest speaking situations most participants were surprised by their feelings. P1 and P2 mentioned that they were surprised that the reading portion was not that "bad", because they only stuttered one or two times during the duration of reading in unison.

\subsection{Additional Considerations}

In preparation for the study, participants were told not to drink caffeine prior to participation. One participant appeared to have exercised immediately prior to participation, which may have influenced the results. Another consideration is that the ambient temperature in the experimental room was warm and may have impacted the results. Data was collected at the end of July, which generated higher than usual temperatures in the area.

\section{Future Directions}

In the future, it is important to consider more naturalistic environments when exploring the interaction between physiological and affective responses to using self-disclosure. Additionally, it is essential to allow for participant variability in identifying and replicating their own easy and difficult speaking situations to add ecological validity to the results of the study. A 
larger sample size is necessary to further understand the implications of using (or not using) self-disclosure statements.

This pilot study has informed the method for future larger scale studies using similar physiological and affective techniques. For example, the baseline of five minutes was noted to be an excessive length of time for participants and researchers. Upon review of the data, a baseline of approximately two minutes would have provided similar information with reduced longevity. Additionally, the experimental conditions did not last for a full five minutes; so, using a shorter baseline period would allow for better comparison to the experimental timeframe. In addition, the anticipation conditions were 10 seconds in length, which may have been too short of a timeframe to capture physiological responses from some participants. Future studies should include a slightly longer baseline to insure data collection.

\section{Conclusion}

The purpose of this study was to explore self-disclosure, physiological and affective responses using a hierarchy of speaking situations to assess self-perceived severity, (2) investigate physiological and affective responses in self-disclosure and non self-disclosure speaking contexts, (3) examine types of self-disclosure statements used along with physiological responses, (4) and gain an understanding of reasons why and how adults who stutter choose to self-disclose or not self-disclose about their stuttering. Four adults who stutter were randomly assigned to self-disclosure and non self-disclosure speaking contexts. Heart rate, skin conductance, and affective responses were measured at the following focus areas: 1) start baseline, 2) anticipation of the easy speaking situation, 3) the easy speaking situation, 4) anticipation of the difficult speaking situation, 5) the difficult speaking situation, and 6) end 
baseline. An informational interview inquiring of the participants use of or lack of self-disclosure was then conducted. There was not a statistically significant difference in the between-group heart rate and skin conductance results, but there was during the end of the baseline of the BPM measurements. Also, it was also suggested that the anticipation of easy or difficult speaking situation (SC and HR) may be influenced based on familiarity or comfortableness of situation. Participants who did not self-disclose reported the same affective responses pre- and post-experiment, while participants who did self-disclose reported different affective responses pre- and post-experiment. Additionally, the informational interview gave insight into how the participants' perceived fear of a speaking situation was different than anticipated. The interview also provided information about the situations that participants self-disclose most often (e.g. interviews, beginning of an interaction/first meeting, on the phone) and how they self-disclose. This study also revealed that self-disclosure is still a valuable tool that can ease conversation for the speaker. Furthermore, self-disclosure appears to elicit various affective and physiological responses, compared to not using self-disclosure, depending on the participant's personal experiences with the speaking situation. These results may help clinicians to inform their therapy by considering multiple variables and how they change depending on the client's experiences. 
Appendix A. Self-Assessment Manikin
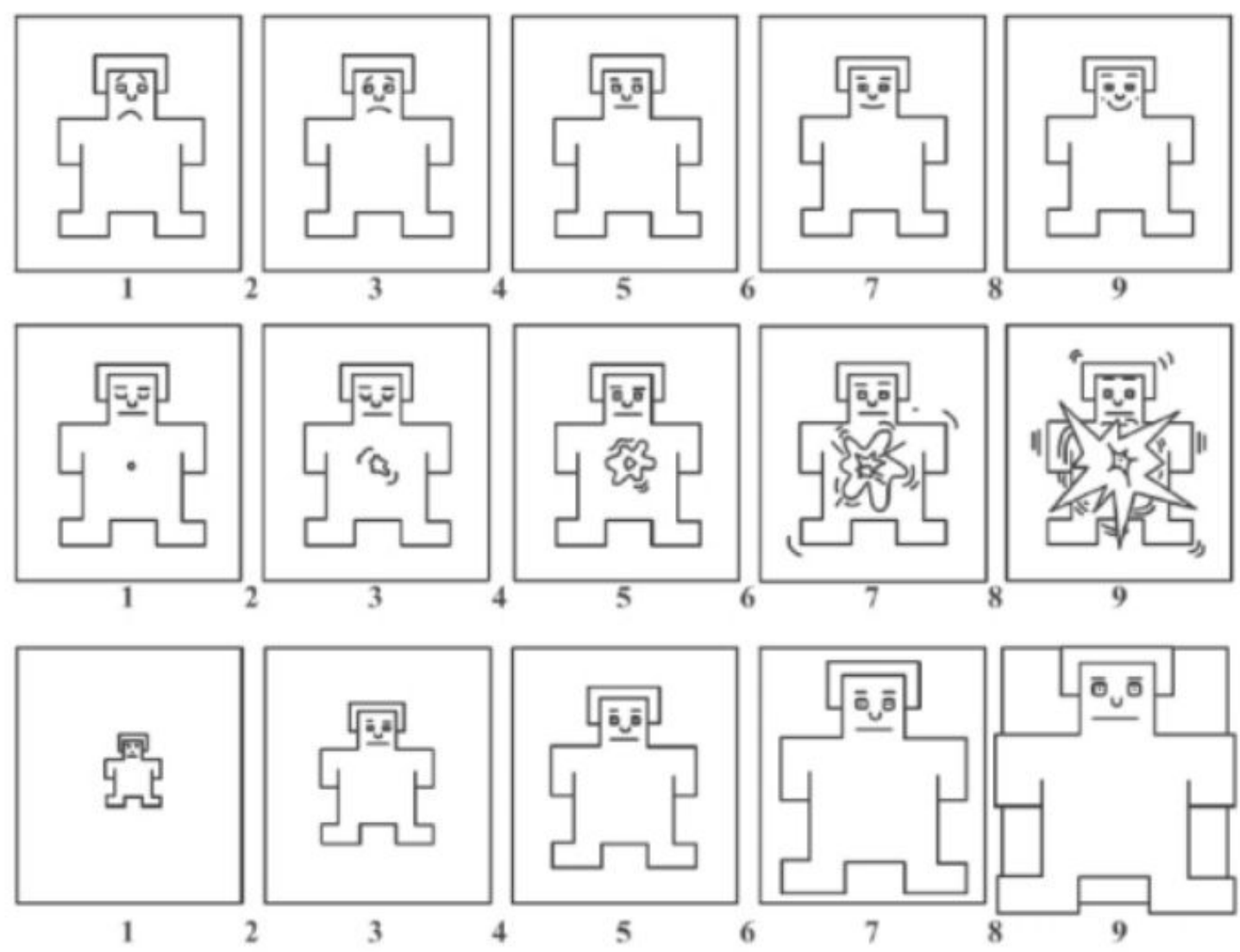


\section{Appendix B. Informational Interview Questions}

1. Why do you choose to self-disclose?

2. When you self-disclose do you do it for the listener or for yourself?

3. How do you self-disclose? Verbal or non-verbal (e.g., shirt, CV/resume,etc.)

4. Could you describe how you feel when you self-disclose?

5. When did you first learn about self-disclosure?

6. What type of verbal self-disclosure statements do you use? In which situations do you use these statements?

7. Are there other aspects of your identity that you choose to self-disclose?

8. How did you feel about engaging in both your most difficult and easiest rated speaking situations?

9. Is there anything you would like to add? 


\section{Appendix C. Rainbow Passage}

\section{The Rainbow Passage}

When the sunlight strikes raindrops in the air, they act as a prism and form a rainbow. The rainbow is a division of white light into many beautiful colors. These take the shape of a long round arch, with its path high above, and its two ends apparently beyond the horizon. There is, according to legend, a boiling pot of gold at one end. People look, but no one ever finds it. When a man looks for something beyond his reach, his friends say he is looking for the pot of gold at the end of the rainbow. Throughout the centuries people have explained the rainbow in various ways. Some have accepted it as a miracle without physical explanation. To the Hebrews it was a token that there would be no more universal floods. The Greeks used to imagine that it was a sign from the gods to foretell war or heavy rain. The Norsemen considered the rainbow as a bridge over which the gods passed from earth to their home in the sky. Others have tried to explain the phenomenon physically. Aristotle thought that the rainbow was caused by reflection of the sun's rays by the rain. Since then physicists have found that it is not reflection, but refraction by the raindrops which causes the rainbows. Many complicated ideas about the rainbow have been formed. The difference in the rainbow depends considerably upon the size of the drops, and the width of the colored band increases as the size of the drops increases. The actual primary rainbow observed is said to be the effect of super-imposition of a number of bows. If the red of the second bow falls upon the green of the first, the result is to give a bow with an abnormally wide yellow band, since red and green light when mixed form yellow. This is a very common type of bow, one showing mainly red and yellow, with little or no green or blue.

From Fairbanks, G. (1960). Voice and articulation drillbook, $2^{\text {nd }}$ edn. New York: Harper \& Row. pp124-139. 


\section{References}

Alm, P. A. (2004). Stuttering, emotions, and heart rate during anticipatory anxiety: A critical review. Journal of Fluency Disorders, 29(2), 123-133.

Bowers, A., Saltuklaroglu, T., \& Kalinowski, J. (2012). Autonomic arousal in adults who stutter prior to various reading tasks intended to elicit changes in stuttering frequency. International Journal of Psychophysiology, 83(1), 45-55.

Boyle, M. P., Milewski, K. M., \& Beita-Ell, C. (2018). Disclosure of stuttering and quality of life in people who stutters. Journal of Fluency Disorders, 58, 1-10.

Byrd, C. T., Croft, R., Gkalotsi, Z., \& Hampton, E. (2017). Clinical utility of self-disclosure for adults who stutter: Apologetic versus informative statements. Journal of Fluency Disorders, 54, 1-13.

Byrd, C. T., McGill, M., Gkalitsiou, Z., \& Cappellini, C. (2017). The Effects of Self-Disclosure on Male and Female Perceptions of Individuals Who Stutter. American Journal of Speech-Language Pathology, 26(1), 69.

Dietrich, S., \& Roaman, M. H. (2001). Physiologic arousal and predictions of anxiety by people who stutter. Journal of Fluency Disorders, 26(3), 207-225.

Kang, C., Riazuddin, S., Mundorff, J., Krasnewich, D., Friedman, P., Mullikin, J. C., \& Drayna, D. (2010). Mutations in the Lysosomal Enzyme-Targeting Pathway and Persistent Stuttering. New England Journal of Medicine, 362(8), 677-685.

Geethanjali B, Adalarasu K, Hemapraba A, Kumar SP, Rajasekeran R. Emotion analysis using SAM (SelfAssessment Manikin) scale. Biomed Res 2017; 28: S18- S24.

Healey, E. C., Gabel, R. M., Daniels, D. E., \& Kawai, N. (2007). The effects of self-disclosure and non self-disclosure of stuttering on listeners' perceptions of a person who stutters. Journal of Fluency Disorders, 32(1), 51-69.

Guntupalli, V. K., Everhart, D. E., Kalinowski, J., Nanjundeswaran, C., \& Saltuklaroglu, T. (2007). Emotional and physiological responses of fluent listeners while watching the speech of adults who stutter. International Journal of Language \& Communication Disorders, 42(2), 113-129. 
Guntupalli, V. K., Kalinowski, J., Nanjundeswaran, C., Saltuklaroglu, T., \& Everhart, D. E. (2006). Psychophysiological responses of adults who do not stutter while listening to stuttering. International Journal of Psychophysiology, 62(1), 1-8.

Mcgill, M., Cullen, L., \& Webb, H. (2019). Clients Experiences of Telepractice for Stuttering. Perspectives of the ASHA Special Interest Groups, 4(3), 553-562.

Mcgill, M., Siegel, J., Nguyen, D., \& Rodriguez, S. (2018). Self-report of self-disclosure statements for stuttering. Journal of Fluency Disorders, 58, 22-34.

Sitek, K. R., Cai, S., Beal, D. S., Perkell, J. S., Guenther, F. H., \& Ghosh, S. S. (2016). Decreased Cerebellar-Orbitofrontal Connectivity Correlates with Stuttering Severity: Whole-Brain Functional and Structural Connectivity Associations with Persistent Developmental Stuttering. Frontiers in Human Neuroscience, 10.

Tran, Y., Blumgart, E., \& Craig, A. (2011). Subjective distress associated with chronic stuttering. Journal of Fluency Disorders, 36(1), 17-26.

Warriner, A. B., Kuperman, V., \& Brysbaert, M. (2013). Norms of valence, arousal, and dominance for 13,915 English lemmas. Behavior Research Methods, 45(4), 1191-1207.

Zhang, J., Kalinowski, J., Saltuklaroglu, T., \& Hudock, D. (2010). Stuttered and fluent speakers heart rate and skin conductance in response to fluent and stuttered speech. International Journal of Language \& Communication Disorders, 45(6), 670-680. 